\title{
Networked Service Innovation Process in the Production of a New Urban Area
}

\author{
Erja Väyrynen and Riitta Smeds \\ Helsinki University of Technology TKK, Enterprise Simulation Laboratory SimLab, \\ P.O. Box 9220, FI-02015 TKK, Finland \\ erja.vayrynen@tkk.fi, riitta.smeds@tkk.fi
}

\begin{abstract}
When a newly completed urban area does not conform to the visions, this brings disappointment for the residents and losses for the service providers in the area. In order to specify process innovations required in urban development, we conceptualise new urban areas as service innovations, and compare urban development to new service development. We conclude that developing urban areas as a process of customer-oriented service development and production is likely to lead to the satisfaction of all stakeholders.
\end{abstract}

\section{Introduction}

New urban areas require heavy investments and involve a large number of actors during the long process from visions to implementation. However, the users find the completed built environment often unsatisfactory. The residents may complain about construction defects or about missing services, and the service providers may find their location quite unsuitable for attracting clients. The developers may be in trouble with unsold flats. Our assumption is that this kind of situation calls for innovative new solutions, not only for the end-product, i.e. the built environment, but even more importantly, for the process that produces this output. In this paper, we raise the following question: What kind of process innovations could be used to mediate innovative ideas throughout the urban development process, from visioning to use?

In our earlier study, we have conceptualised new urban areas in a novel way as service innovations: as physical, social, environmental, economic, technological, aesthetic, etc. configurations that support the customers (i.e. residents and other users of the area) in their daily living and enable their manifold activities [1]. We applied the theories of process management and new service development (NSD), and considered the users of a new area as customers that continuously co-develop this service. We assumed that a successful design and timing of customer involvement enhance the quality of a service innovation and help manage the complex user expectations, and thus increase customer satisfaction. We concluded that process innovations would be needed to promote this kind of networked co-development. We continue in this paper by comparing urban development to NSD and by analysing the result from the customer perspective. Our final aim is to develop a new model of urban development, considered as a networked service development process. 


\section{Background}

The process of urban development, from visioning and goal setting to implementation and use, is commonly modelled as presented in Fig. 1.

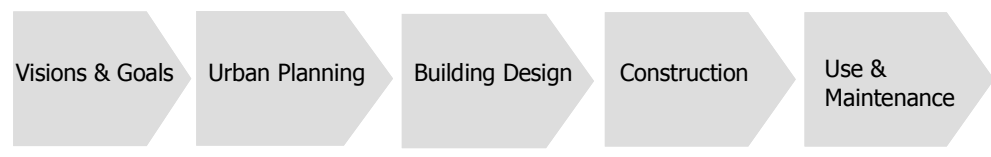

Fig. 1. The process of urban development

When we remodel this conventional process by emphasising the amount of new ideas and alternatives under consideration in each stage of the process and by showing the main actors, we are able to discern some problematic points in the conventional urban development process (Fig. 2).

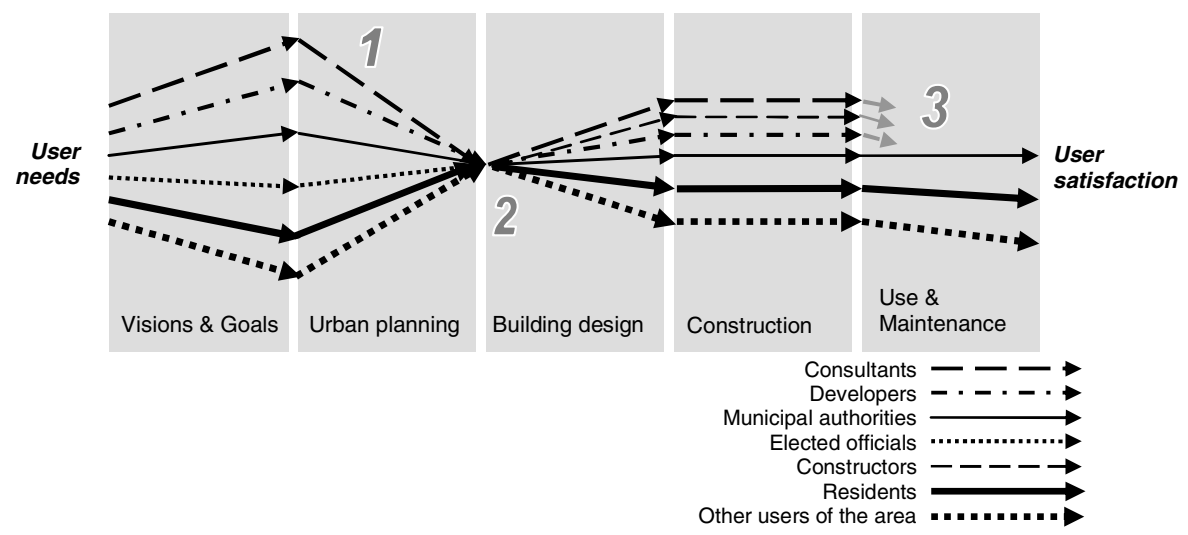

Fig. 2. Conventional process of urban development with main actors

The points of concern are the following (ref. numbering in Fig. 2): 1. Visions do not steer implementation, 2. Discontinuity in the information transfer, 3. Lack of interest in the phase of use and maintenance

We have studied the urban development process through in-depth case studies of four innovative housing areas: Suurpelto, "the Garden city of information age" (Case 1), Viikki, "the Ecological city" (Case 2), Vuores, "the Small town in the midst of nature" (Case 3), and Nupuri, "Individual design for a coherent community" (Case 4). In these case studies, we found certain innovative practices that had been developed to mitigate the above mentioned process deficiencies. We interpreted these empirical findings through a theoretical framework and defined three new generic principles of urban development:

A. Vision guides the process from planning to implementation

B. Continuous learning and interaction act as a support for innovation

C. Commitment of all actors to quality leads to user satisfaction. 
To develop a new model of urban development as a networked service innovation process, these principles are now further analysed and tested based on the theories of new service development.

\section{Theoretical Scope}

Services differ from physical products, which brings particular features also to their development efforts. Several studies show, nevertheless, that many of the concepts originating from the new product development (NPD) literature are also applicable to service companies. Customer-oriented NPD requires collecting knowledge about the customers' needs in a systematic way and designing products based on this knowledge; the same applies to services.

Grönroos [2] points out that services are processes by nature. They are produced and consumed at least partly simultaneously, and the customer participates in the production of the service. The simultaneity of production and consumption, and the customer's participation, make it even more important to involve customers in the development efforts than in the case of physical products.

Innovations in services can be related to changes in various dimensions: in the service concept, in the client interface, in the delivery system, in technological options etc. [3]. Most innovations would involve a combination of changes in several dimensions. New service ideas may emerge already in the planning of service objectives and strategy [4].

Valkeapää et al. [5] have studied how to enhance customer orientation in NSD in a strategic alliance. They present a new framework illustrating the prerequisites of a customer-oriented NSD process in alliance context (Fig. 3). They point out that collaborative service processes have potential for service innovations, and therefore their development should be encouraged.

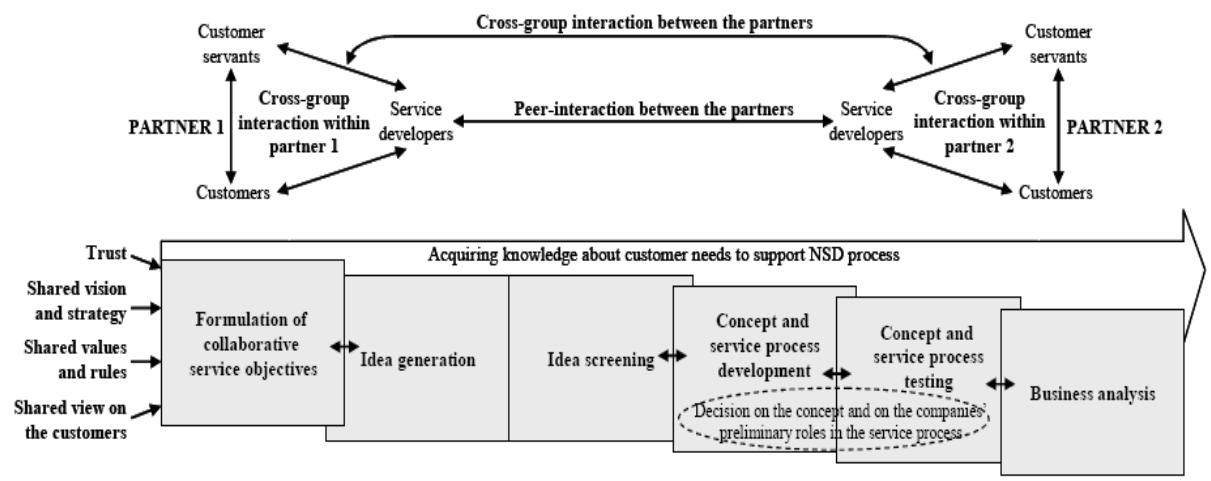

Fig. 3. The model of a customer-oriented NSD process in a strategic alliance, with the model of interaction [5]

According to the conclusions of Valkeapää et al. [5], joint service processes in alliance context easily become complex, which highlights the importance of a carefully planned and collaborative development. In their framework, Valkeapää et al. have 
modelled a NSD process in a case study of a strategic alliance of two partner companies. The case alliance consisted of an insurance organization (Partner 1, in Fig. 3) and a group of banks (Partner 2). The model also includes various methods for identification of customer needs in each stage of the service development process.

Based on their case study, Valkeapää et al. [5] confirm that factors such as shared vision, values, and rules were important prerequisites for the NSD in the case alliance. Another important prerequisite for the development of the new collaborative service was a shared view on the customers, which also contributed to trust between the partners. The study [5] further highlights the significance of interaction between different parties in the collaborative NSD process. A collaborative NSD process should support peer-interaction between the personnel of the strategic partners. This peer-interaction between the partners is crucial in order to build common vocabulary and consensus about the collaborative service.

A special emphasis should also be put to the interaction with customers through the service process, in order to discover customer needs. In the case studied by Valkeapää et al., the phases of concept and service process development and testing included interaction between the service developers, the customer servants, and the representatives of customers. This cross-group interaction should take place within one company but also between the partners [5].

In this paper, we compare the model of interaction and the process model ([5], Fig. 3) analytically with the development process of a new urban area. The similarities identified in this comparison are tested in our four cases, to develop hypotheses for an innovative service-oriented urban development and production process.

\section{NSD in the Context of Urban Planning: Model of Interaction}

In a process of urban development, the network of actors consists of a challenging variety of actors: e.g. municipal authorities, elected officials, land owners, developers, consultants and service providers, as well as residents and other users of the area. Interaction in this kind of network is not a simple task. Hänninen et al. [6] argue that such a network calls for several management methods: e.g. coordination of resources and network members, as well as encouragement of collaboration, learning, trust and sharing of information.

We assume that the model of interaction presented in Fig. 3 can contribute to the refinement of the process of urban development by structuring in a new way the interaction required during the process. Instead of two companies, as in Fig. 3, we have inserted in the model the two main groups of key actors in urban development (Fig. 4). The Group 1 consists of public actors: municipal authorities (e.g. urban planners) and elected officials. The Group 2 includes private actors: developers, construction companies and service providers together with consultants (e.g. architects and engineers). Following the model of Valkeapää et al., these groups should practise interaction both within the group and between the groups. In addition, they should regularly interact with their customers, i.e. the future residents or other users of the new urban area, and also create a shared view of their customers. 


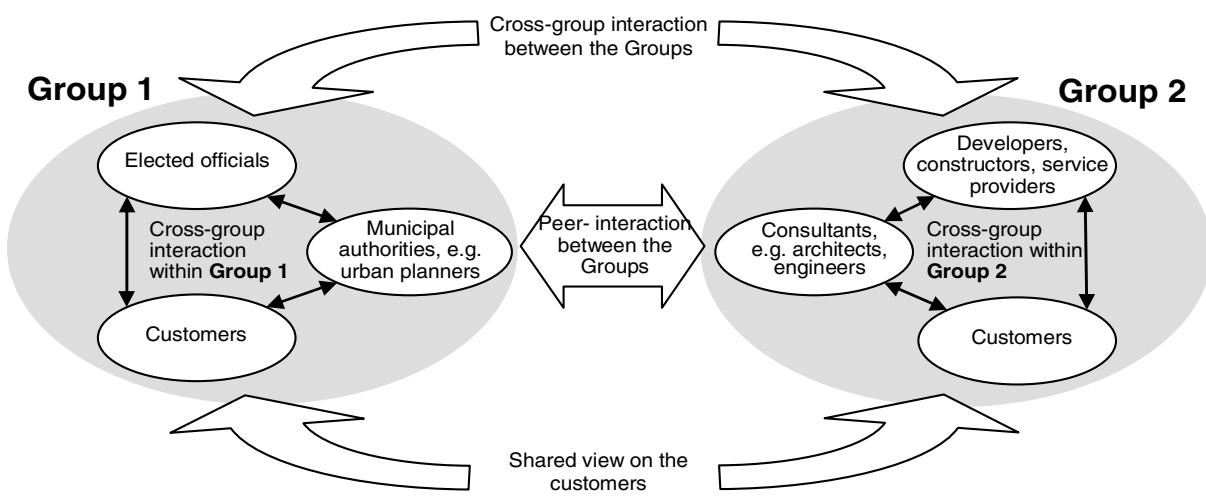

Fig. 4. Interaction between the key groups in urban development (modified from [5] )

The three new principles, suggested earlier in Chapter 2, are now analysed through the model of interaction presented in Fig. 4.

A. Vision guides the process from planning to implementation. Visions are usually created within Group 1, and they are implemented by Group 2. Our case studies indicate that cross-group interaction between the groups is essential for a successful implementation of visions, and that this interaction should be carried on already from the early phases of the process. The case studies 2 and 3 also reveal the importance of deriving measurable criteria from the vision in order to enhance innovation. The use of criteria increases the understanding of the common goals, and also serves as a practical tool during the follow-up of the implementation.

The end users of the future area or their representatives were not involved in the visioning process in any of the cases studied. Compared to a NSD process, this implies that a significant potential for innovation is usually being lost.

B. Continuous learning and interaction act as a support for innovation. The discontinuity in the information transfer, illustrated as No. 2 in Fig. 2, occurs at the same time when the main responsibility of the process moves on from Group 1 to Group 2 . In all the cases studied, new practices were created to urge developers and constructors to examine carefully the information produced in the visions and plans for the area. In addition to cross-group interaction, this necessitates peer-interaction between the groups.

In one of the cases, residents were included in the interaction through an innovative web based on-line participation method, the Planning Forum (Case 4). This enabled cross-group interaction within Group 1, which is generally neglected. (Residents' statutory participation in the urban planning process does not comply here with the definition of interaction.) In the Planning Forum, a special content management system enables maintaining the material related to the planning projects, including conversation and comments, for years. All users have access to the stored content. This offers a new opportunity to exploit the potential for innovations, as referred to in the NSD process. In addition to interaction with customers, the Planning Forum also provides a possibility for Group 1 and Group 2 to create a shared view on the customers. 
C. Commitment of all actors to quality leads to user satisfaction. The perspective of service innovation process to urban development highlights the satisfaction of end users as a main goal of the process. This implies that the new urban area should provide a good physical environment that enables all the activities needed for satisfactory living, working, moving etc. The co-developing of the corresponding services may have started during the planning stage, but co-producing and consuming of these services really take off when the construction is accomplished and the long phase of use and maintenance start. This is also when the expectations of the users, raised during the previous phases, should be met. However, in the conventional urban development process, the main actors of the process do not show sufficient interest in the phase of use and maintenance.

Our case studies indicate one reason for the above mentioned problem. The actors of the implementation network (Group 2 in Fig. 4) usually have very few connections to the early stages of the process, and thus have difficulties to be committed to quality targets that have been set by quite another group of actors (Group 1). We assume that a shared view on the customers is the prerequisite for both groups to understand the importance of creating and maintaining customer satisfaction after the completion of a new area. In one the cases, residents could act as co-producers by using a special tool for selection of optional elements to shape their future environment (Case 4). This method can increase cross-group interaction within Group 2 and enhance the commitment of all its actors to quality.

Table 1 summarises the different modes of interaction typically related to each of the new principles for the innovative development of new urban areas.

Table 1. Modes of interaction typical to each new principle (shaded cells)

\begin{tabular}{|l|c|c|c|}
\hline & \multicolumn{3}{|l|}{ Three new principles for urban development } \\
\hline Modes of interaction & A & B & C \\
\hline $\begin{array}{l}\text { Cross-group interaction between } \\
\text { the Groups }\end{array}$ & & & \\
\hline $\begin{array}{l}\text { Cross-group interaction within } \\
\text { the Group }\end{array}$ & & & \\
\hline $\begin{array}{l}\text { Peer- interaction } \\
\text { between the Groups }\end{array}$ & & & \\
\hline $\begin{array}{l}\text { Interaction with customers and shared } \\
\text { view on the customers }\end{array}$ & & & \\
\hline
\end{tabular}

\section{NSD in the Context of Urban Planning: Process Model}

Two features of the NSD process are of particular interest to the urban development process: Firstly, the importance of developing and testing the service concept already in the early phases of the collaborative NSD process, along with the service process; And secondly, acquiring knowledge about customer needs throughout the NSD process to support service innovation.

The conventional process for urban planning (cf. Fig. 2) is aimed at achieving a document called the local detailed plan, and the processes of building design and construction are aimed at achieving the physical environment consisting of buildings, 
streets and parks. None of these processes is given the task of considering the service concept, not to mention the service process, of a new urban area.

The areas chosen for our case studies were all innovative areas with a strong vision. Some of these visions were developed further in a systematic way, resulting in a service concept followed by some kind of a service process. The case that was the most organised in this procedure, also reached its targets very well (Case 2).

When striving to develop new services that match customers' needs, most attention should be paid to customer input in the idea generation stage of the development process [4]. Furthermore, Jong and Vermeulen [3] advise that the creation of a climate supportive for innovation requires concentrating on both people-related and structural factors in the NSD process. Customer involvement is often claimed to be timeconsuming. Related to time saving, Alam and Perry [4] remind that the stages of idea screening, concept development, concept testing, and business analysis can be carried out in parallel.

Customer needs are seldom studied systematically in the course of an urban development process. Contrary to common suppositions, appropriate techniques can be found for studying customer needs in all process phases. In two of our cases, the future residents were involved in the planning process (Case 1 and Case 4). The methods included e.g. a participative social process simulation method, as well as net based surveys and discussion forums. The impact of this involvement is not yet discernible, because the case areas are still under planning, but the feedback from the other actors in the process has been positive.

\section{Conclusions and Discussion}

This study reveals the following possibilities for process innovations in the urban development process:

1. Customer orientation: It is of particular importance that the two interacting groups, public and private, create a shared view about the customers. The methods of acquiring knowledge about customer needs and the timing of customer interaction have to be adjusted to the different stages of the process.

2. From idea generation to service concept: The interaction between the public and private groups should create a climate supportive for innovation. Customers should be involved in the idea generation, and attention should be paid to the formulation of the service concept as a substantial part of the planning process.

3. Duration of the process: Instead of being organised in a sequential way, as usual, the development process may contain overlapping and parallel stages, which can shorten the lead time of the process. In the case of urban development where the life-cycle of the output is exceptionally long, we suggest, however, that the speed of the process should not be prioritised in the same way as in NSD.

Developing an urban area as a customer-oriented service development and production process is likely to lead to the satisfaction of all stakeholders. According to our new urban development process model, customer needs should be identified at an early stage, and a shared view on the customers should be maintained during the long process of planning and implementation of a new area. Developers and construction companies should be involved in a collaborative innovation process together with 
their public counterparts as well as with the customers, which can bring innovation to the construction business that is usually considered quite reluctant to new ideas. Other service providers that aim to operate in the new urban area should get access to the planning process, which helps them adjust their service offerings to the needs of the future inhabitants and to the physical premises earlier than usual.

The development and production of an urban area as a networked service innovation between the public and private actors and the customers, is a novel approach, both theoretically and in practice. The results raise important hypotheses about the characteristics of urban development processes, to be further tested in multiple case studies. We hypothesise that with a collaborative, service-oriented urban development and production process, a more efficient use of public resources and a higher quality of the built environment will be achieved for the end-users than with conventional processes. The construction companies as well as the service providers will gain the possibility to develop synergistic innovations in this process.

Acknowledgements. The research reported in this paper has been conducted in the OPUS research project at the Enterprise Simulation Laboratory SimLab, Department of Computer Science and Engineering, Helsinki University of Technology TKK. The authors are grateful to the multidisciplinary OPUS research team for their creative research effort. The research is financially supported by the Finnish Funding Agency for Technology and Innovation Tekes, with municipalities and companies, which is gratefully acknowledged.

\section{References}

1. Väyrynen, E., Smeds, R.: Urban Planning as a Networked Development Process of Service Innovation. In: Smeds, R. (ed.) Proceedings of the APMS 2008 International Conference on Innovations in Networks, pp. 591-601. Helsinki University of Technology TKK, Finland (2008)

2. Grönroos, C.: Adopting a service logic for marketing. Marketing Theory 6(3), 317-333 (2006)

3. De Jong, J.P.J., Vermeulen, P.A.M.: Organizing successful new service development: a literature review. Management decision 41(9), 844-858 (2003)

4. Alam, I., Perry, C.: A customer-oriented new service development process. Journal of Services Marketing 16(6), 515-534 (2002)

5. Valkeapää, E., Södergård, R., Jaatinen, M., Smeds, R.: New Service Development Process in a Strategic Alliance. In: Proceedings of the 13th International Product Development Management Conference, Milan, pp. 1487-1501. EIASM and Politecnico di Milano (2006)

6. Hänninen, K., Huhta, E., Väyrynen, E.: Management of Change in Complex Networks. In: Smeds, R. (ed.) Proceedings of the APMS 2008 International Conference on Innovations in Networks, pp. 293-302. Helsinki University of Technology TKK, Finland (2008) 